\title{
Shrinking-swelling of clay under the effect of hydric cycles
}

\author{
Amal Medjnoun ${ }^{1} \cdot$ Ramdane Bahar $^{1}$
}

Received: 30 May 2016/ Accepted: 2 November 2016/Published online: 21 November 2016

(C) Springer International Publishing Switzerland 2016

\begin{abstract}
Views the scarcity of building sites, the urban development on soils with problems such as swelling soils, causes the damage to lightweight structures, as a sewerage networks, shod, etc. These damages are often classified in the low risk category. However, the neglect of these disorders can create geotechnical problems, much more complicated, with high risk, as a land motion. This case of disorders has been recording in several regions in Algeria, as example: Ain Defla, Boumerdes, and Medea, which is the studied case in this paper. The geotechnical study and the swelling tests on undisturbed and remolded samples, indicate the presence of a high swelling clay layer, of about 3-4 m deep. This research focuses on the evolution of the phenomenon of shrinking and swelling under the effect of a set of parameters existing in situ, such as climate cycles (alternating between winter and summer) and the effect of soil saturation mode. In this work, two modes are studied: saturation by infiltration and saturation by capillary. The results analysis shows the remolding of samples structure and the loss of their initial mechanical and physical properties. The test results justify the observed disorder on the site such as the erosion of foundation soils under the effect of the flow of surface water, and landslide triggering, affecting the whole of the site, and endanger the university campus located on this site.
\end{abstract}

Keywords Swelling-shrinking $\cdot$ Water flow $\cdot$ Climate cycles · Ground motion

Amal Medjnoun

medjnounamel@yahoo.fr

1 University of sciences and technology Houari Boumediene, Algiers, Algeria

\section{Introduction}

The swelling phenomenon of some geological clay formations, with high plasticity index, makes serious problems in several countries of the world such as those located in arid and semi arid climatic areas. This phenomenon causes significant disorders in the structures, because of extreme weather conditions. All types of structures, based on these soils, suffer damage. The examples of disorders related to the presence of swelling clays, are wide and varied [9]. In Algeria, the swelling clay soils are widespread, and many regions as: In-Amenas In-Salah, Medea, M'sila, Tlemcen, Mostaganem, etc., are affected. Many cases of structures disorders have been identified [2, 6, 7].

This phenomenon still continues to occur in many areas and causes considerable damage every year, particularly in light constructions.

Many studies have been conducted to simulate deformations caused by seasonal variations represented by cyclic water solicitation, such as the work of Chen and Ma [4]; Subba Rao and Satyadas [10], Al-Homoud et al. [1], Basma et al. [3], Tripathy et al. [11], Geremew et al. [8]. They studied the shrinkage phenomenon swelling on disturbed and compacted soils.

Although these works are not carried out under identical conditions, for the majority of them, there is a stabilization of the phenomenon of swelling-shrinkage after four or five cycles. The results of Tripathy et al. [11], in particular, shows that the effect of the initial conditions is almost zero after four or five cycles of wetting-drying, and swelling shrinkage phenomenon depends mainly on the type of clay $[12,5]$.

According Geremew et al. [8], the results obtained on specimens alternately subjected to total wetting phases and complete drying phases, show that during the first cycle, 
Fig. 1 Presentation of the campus site on an extract of the geological and topographical map of the Medea region, sheet 86 , scale 1:50,000

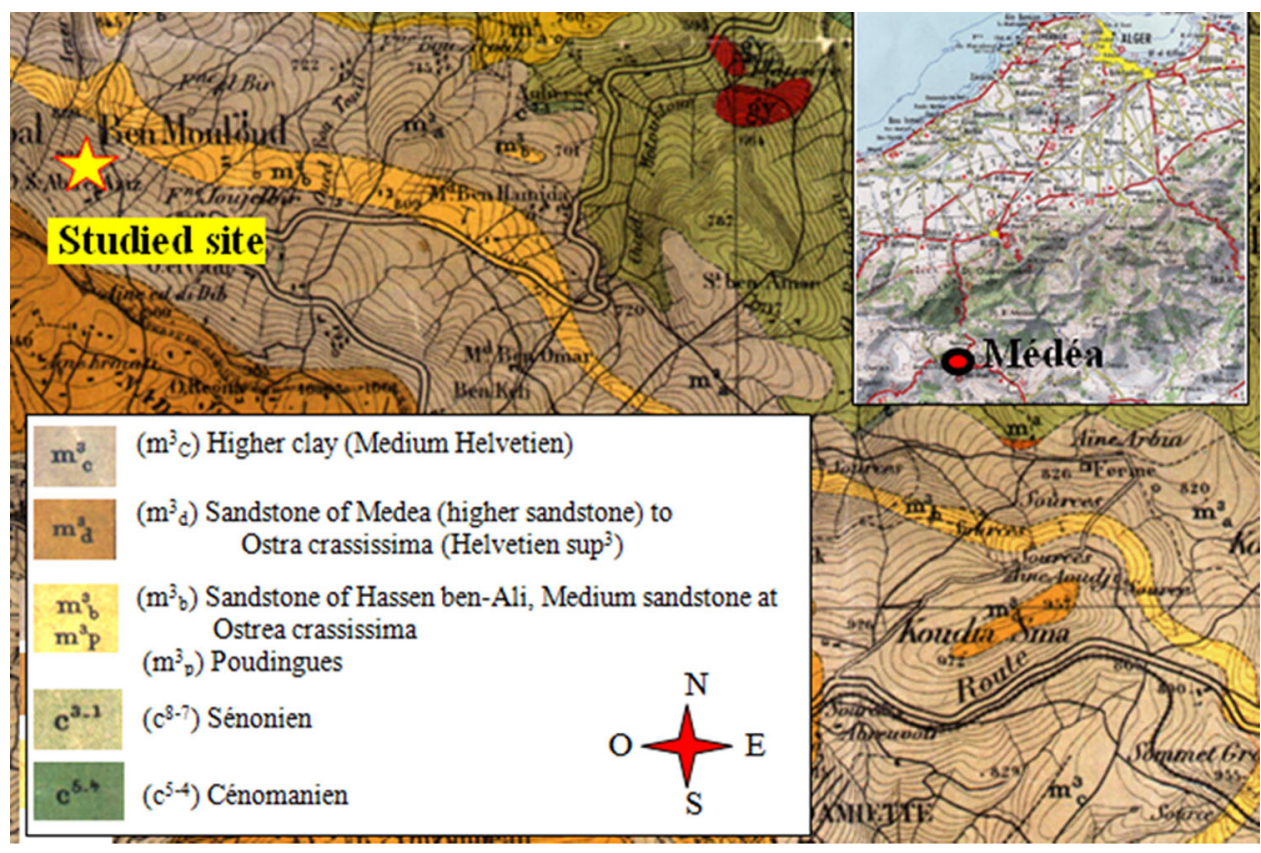

the cracks caused by drying increases soil permeability, and influences the swelling kinetics in the next cycle. In all samples of the same cyclic testing a stabilization of deformations will start from the third cycle. However, all samples showed an increase of the cumulative swelling during cycles. The deformation caused by shrinkage and swelling is not completely reversible.

This article presents and discusses various pathological cases observed in the university campus, located in Medea site, related to swelling and shrinking phenomenon.

In this paper, the cyclical climatic solicitations are carried out in a climatic room, with the aim of adding the effect of all the climatic parameters on the ground such as the temperature, humidity and rainfall and studying their effect on swelling clay. The values of this parameters were obtained from the climatic data of the Medea region. The soil used is a swelling clay extracted about $5 \mathrm{~m}$ deep Medea site. The test is run on undisturbed soil.

\section{Site description}

The administrative center of Medea is located about $80 \mathrm{~km}$ south of Algiers, in the center of the Tellien Atlas, characterized by a high altitude and hilly ground. Medea is characterized by a sub-humid Mediterranean climate, dry and hot in summer with temperatures can reach $40^{\circ} \mathrm{C}$, and a rainy, snowy winter with temperatures between -1 and $5^{\circ} \mathrm{C}$. These temperatures were noticed much in the last 5 years. The temperature variations and moisture are repeated every year, and form a wetting-drying cycle. These climatic changes are triggers an initial state modification of expansive soils. In the presence of water in liquid or vapor form, expansive soils increase in volume. Under the effect of heat, the soil undergone shrinkage, which creates cracks in all directions with different dimensions. The university campus site is located in the north of Medea city (Fig. 1). Lithostratigraphy and geology of Medea is composed, in depth, of a marl-calcareous formation, with a predominance of consolidated marly benches and topped by a layer of clay.

According to the geotechnical investigation, the North of Medea composed essentially of a grayish marl bedrock sometimes blueish very compact in depth. This substratum is surmounted by a layer of marly clay brownish or grayish and greenish color, gray tinged with yellow color in some places. These marly clays contain sometimes blocks of sandstone beige or yellowish color, with centimetric dimensions in some places. Whitish color of carbonate nodules are also found in this marly clay layer, whose thickness varies between 2.00 and $6.50 \mathrm{~m}$. A layer of topsoil about $0.50 \mathrm{~m}$ covers the whole. The site has undergone a landslide just after completion of the campus, the causes of this phenomenon are the subject of this work.

\section{The analysis of geotechnical data}

A geotechnical investigation was carried out on the site of the university campus located in Medea. Intact samples are taken of each soil layer to submit them to the various geotechnical tests. Some samples were also collected in the vicinity of a break line. The obtained results are summarizing in Tables 1 and 2.

Piezometers tests showed the absence of a groundwater in the studied site. From Table 2, the studied site soil is dense, weakly 
Table 1 Results of geotechnical tests

\begin{tabular}{lllllllllllllll}
\hline Sample & Deep $(\mathrm{m})$ & $\gamma_{\mathrm{d}}\left(\mathrm{kN} / \mathrm{m}^{3}\right)$ & $w \%$ & $\mathrm{~S}_{\mathrm{r}} \%$ & $\mathrm{Ac}$ & $\%<2 \mu \mathrm{m}$ & $C_{\mathrm{CD}}(\mathrm{kPa})$ & $\varphi\left({ }^{\circ}\right)$ & $P_{\mathrm{c}}(\mathrm{kPa})$ & $C_{\mathrm{c}}(\%)$ & $S_{\mathrm{i}}(\%)$ & $S_{\mathrm{p}}(\mathrm{kPa})$ & $S_{\mathrm{a}}(\%)$ \\
\hline E-1 & $1.8-2$ & 18.0 & 11 & 62 & - & 48 & 92 & 9.1 & 700 & 14 & 4.5 & 400 & - \\
& $8-8.3$ & 17.5 & 12 & 64 & - & - & - & - & 420 & 28 & 12 & - & - \\
E-3 & $9-9.2$ & 21.8 & 5 & 62 & - & - & - & - & - & - & - & - & - \\
E-6 & $0.6-0.8$ & 18.5 & 13 & 81 & - & - & 40 & 4 & - & - & - & - & - \\
E-10 & $0.5-1$ & 18.3 & 10 & 60 & 1.6 & 53 & 177 & 5.2 & 800 & 15 & 10 & 420 & 12 \\
& $7.5-7.8$ & 18.2 & 13 & 76 & - & - & 65 & 40 & 900 & 8 & 7 & 800 & - \\
E-12 & $1.2-1.4$ & 18.4 & 13 & 76 & 2.0 & 57 & 239 & 12 & - & - & - & - & - \\
\hline
\end{tabular}

Table 2 Geotechnical parameters near the break line

\begin{tabular}{lllllllllllll}
\hline Sample & Deep $(\mathrm{m})$ & $\gamma_{\mathrm{d}}\left(\mathrm{kN} / \mathrm{m}^{3}\right)$ & $w(\%)$ & $S_{\mathrm{r}}(\%)$ & $\mathrm{Ac}$ & $\begin{array}{l}F<2 \mu \mathrm{m} \\
(\%)\end{array}$ & $C_{\mathrm{CD}}(\mathrm{KPa})$ & $\varphi\left({ }^{\circ}\right)$ & $P_{\mathrm{c}}(\mathrm{kPa})$ & $C_{\mathrm{c}}(\%)$ & $S_{\mathrm{i}}(\%)$ & $S_{\mathrm{p}}(\mathrm{kPa})$ \\
\hline E-4 & $2-2.4$ & 15 & 30 & 100 & - & - & 28 & 25 & 50 & 40 & 10 & 70 \\
& $3.5-3$ & 15 & 24 & 100 & - & - & 18 & 20 & - & - & - \\
& $5-5.5$ & 15 & 24 & 100 & - & - & 14 & 13 & 77 & 35 & 14 & 80 \\
& $6-6.4$ & 17 & 9 & 65 & 1.3 & 48 & - & - & - & - & - \\
& $8.5-9$ & 19 & 8 & 56 & - & - & 220 & 11 & - & - & - \\
& $9.1-9.6$ & 18 & 12 & 65 & - & - & 67 & 40 & - & - & - \\
\hline
\end{tabular}

to moderately moist. The clay fraction is greater than $40 \%$. The Casagrande abacus shows a high plastic clay (Fig. 2). The activity (Ac) is greater than 1.25 , it reflects an active clay soil. The mechanical characteristics indicates high shear strength at different depths, high cohesion $\left(C_{\mathrm{cd}}\right)$ and an appreciable friction angle $(\varphi)$ (characteristics of dry clay soils). Preconsolidation pressure $\left(P_{\mathrm{c}}\right)$ is greater than $200 \mathrm{kPa}$ and the compressibility index $\left(C_{\mathrm{c}}\right)$ is between 8 and $28 \%$, indicating a medium and strong compressible soil. The swelling test results show that: the swelling indexes $\left(S_{\mathrm{i}}\right)$ are between 7 and $12 \%$, and the swelling pressures $\left(S_{\mathrm{p}}\right)$ are higher than $400 \mathrm{kPa}$ (characteristics of swelling soils). These tests were doing to identifying the causes of observed ground motion in the studied site. Hence, Table 2.

At the near of break line, the soil consists of an active clay. It is moist and moderately dense above $5 \mathrm{~m}$ of deep,

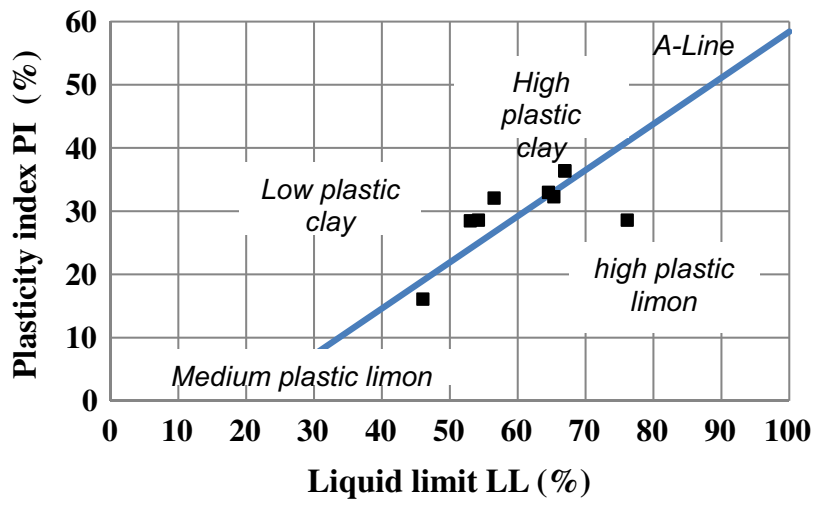

Fig. 2 Presentation of university campus values in Casagrande abacus and moderately moist and dense below $5 \mathrm{~m}$ of deep. The shear strength is very low which justifies the loss of mechanical properties after shearing and rupture (Table 2).

\section{Evolution of shear stress before and after swelling}

Shear tests are performed on samples slightly remolded (drying effect), in the subject to study the path of swelling phenomenon on soil's shear strength. The procedure consists to perform shear tests on wet soil and low moist soils. Drying took place under the ambient temperature of laboratory and it causes hardening of the clay samples. Monitoring of water content was necessary to avoid complete curing of the sample, then, the impossibility of hobbing. The results are showing in Table 3.

This operation allowed us to move from soft and low ground, to a hard and strong soil as confirmed by the mechanical characteristics in Table 3, only, by changing its water state. For this reason the landslide are reactivated in winter and stabilized in summer, and the soap layer has the same characteristics as the swelling clay.

\section{Study of the ground motion occurred in the studied site}

\section{Signs of ground motion}

The site has undergone a number of pathologies, they are shown in Fig. 3. This figure provides an overview about 
Table 3 Geotechnical parameters before and after swelling

\begin{tabular}{lllllll}
\hline Samples state S4 & Deep $(\mathrm{m})$ & $\gamma_{\mathrm{d}}\left(\mathrm{kN} / \mathrm{m}^{3}\right)$ & $W(\%)$ & $S_{\mathrm{r}}(\%)$ & $C_{\mathrm{CD}}(\mathrm{kPa})$ & $\varphi\left({ }^{\circ}\right)$ \\
\hline After swelling & $2.00-2.40$ & 15.37 & 29.33 & 100 & 28 & 25.46 \\
Before swelling & & 19.5 & 9.7 & 71.4 & 277 & 1.3 \\
After swelling & $5.00-5.45$ & 15.62 & 23.86 & 100 & 14 & 13.47 \\
Before swelling & & 17.2 & 15.4 & 75.4 & 58.5 & 44.5 \\
\hline
\end{tabular}
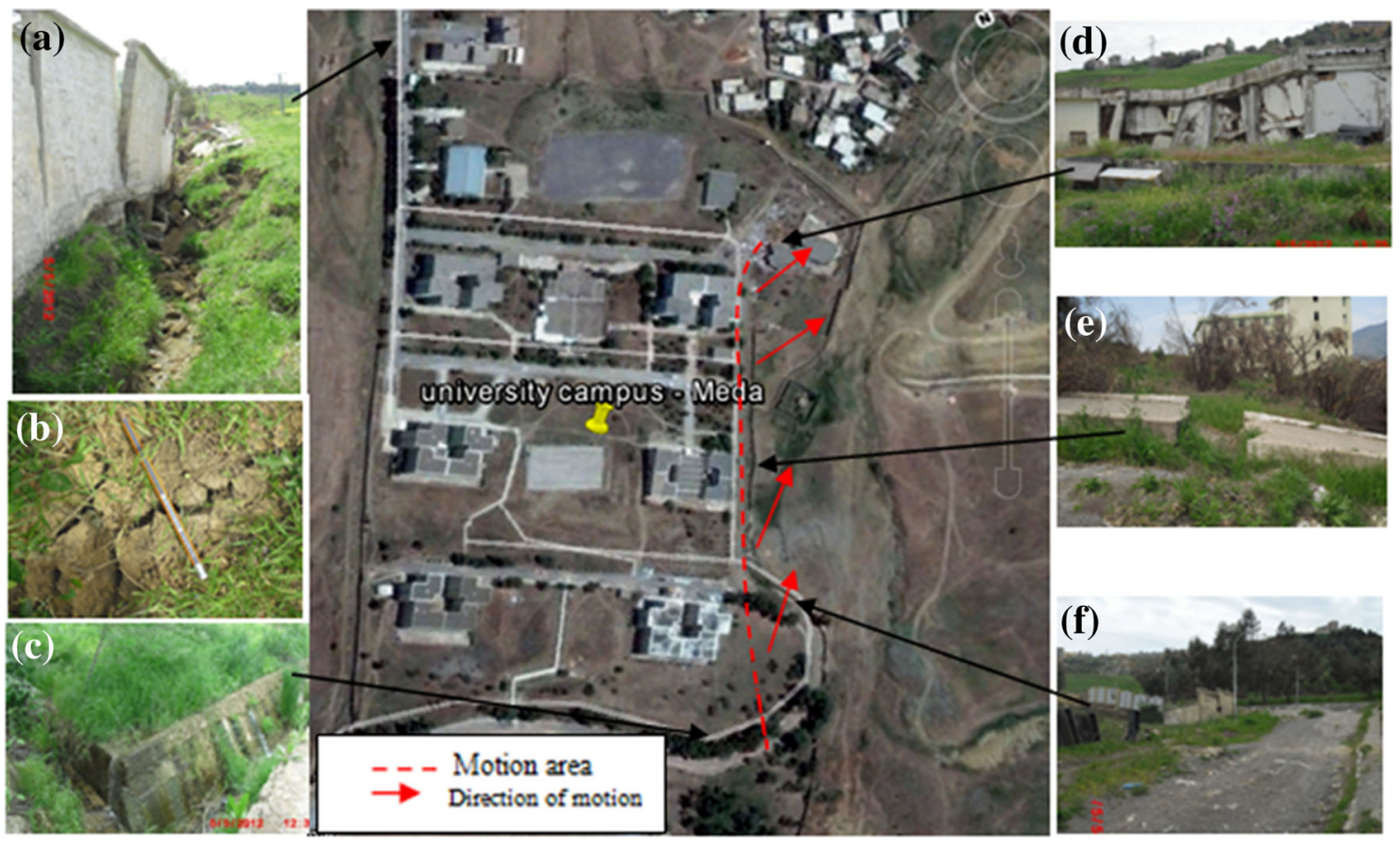

Fig. 3 Presentation of the pathologies observed on the site

land motion observed in the studied site, composed mainly of active clay layer.

An erosion phenomenon is also observed on the slope, Fig. 3a. The soil has undergone shrinking-swelling and became very permeable. The water of damaged sewage network, flows on the surface, following the inclination of the slope. It brings the soil having already had swelling, this soil is easily transported because of the loss of his strength. The permanent flow brings up significant erosion trenches on the studied site, Fig. 3a. A trench crossed the closing walls of the university campus and causing the transport of the foundation soil, and their destruction. Under the effects of seasonal variations, the soil layer has undergone volume changes observed at the form of bulge and opening of shrinkage cracks, Fig. $3 \mathrm{~b}$. This repeated motion has damaged the wastewater networks located about $1 \mathrm{~m}$ from the surface of ground. This allowed the water to flow through shrinkage cracks, and create soap layer in the site. Figure $3 \mathrm{c}$ shows the flow of water upstream of the site. The slide area and break line are exposing in Fig. 3e. Through Fig. 3f, the closing walls, located before the slide area, are also affecting by the ground motion. The bitumen covering the road leading to the northern borderland of the site is damaging, so, the motion has affected the whole south-west part of the site.

The land motion has affected, for now, the lightweight construction, it means that it is probably superficial.

\section{Effect of climate cycles on swelling clay}

In nature, the water flows either from the surface to the depth (direction of gravity) by infiltration phenomenon, or from the depth to the surface (opposite direction of gravity) by capillary action. In this research, the effect of the two paths of water on swelling clays is studied, in extreme climatic conditions (summer and winter). This work is done with the aim to see the effect of water path on the behavior of swelling clays of Medea, in climatic conditions.

The evolution of the structure is followed during the drying-wetting cycles (shrinkage-swelling) by taking pictures at the end of each one. This study is realized on more than one sample. Some results are showed in this paper. 


\section{Test procedure}

The study was conducting on intact identical clay samples and they are cutting from the same block. The samples have a diameter of $63 \mathrm{~mm}$ and a height of $25.4 \mathrm{~mm}$. They are coating laterally, with elastic membranes of low rigidity, to maintain the samples shapes. The test principle involves exposing the samples to alternating cycles of shrinkage and swelling in a climatic room, equipped with a digital program on which the summer and winter characteristics are defined.

Drying (shrinking) is carried out in dry air at a temperature of about $41 \mp 4{ }^{\circ} \mathrm{C}$ and humidity level of $2 \mp 2 \%$ (characteristic of summer), this phase ends when the sample weight becomes constant. After $48 \mathrm{~h}$, the program automatically switches to winter characteristics; with humidity ranging between 92 and $100 \%$, and a temperature of about $1 \mp 2{ }^{\circ} \mathrm{C}$. This phase ends after complete saturation and total swelling samples, generally after $24 \mathrm{~h}$, because of the small sample size.

\section{Presentation of result}

Figure 4 shows the saturation by capillary action and Fig. 5 shows the behavior of samples under the effect of the saturation by infiltration. The geotechnical characteristics of these samples are shown in Table 4. Both samples have a high dry density and a medium water content.

\section{Wetting of clay by capillary action}

At the start of capillary wetting stage, the dry upper part of this sample has undergone a slight raising, then a bursting, this behavior comes from push applied by the lower part swollen. In addition, a significant deformation and cracks are observed, in the vertical direction. The sample has crumbled gradually during the wetting-drying cycles and was cracked vertically and horizontally. The sample does not return to its original dimension after shrinkage and it undergone a cumulus swelling during the following shrinking and swelling cycles.

A thin whitish color layer gradually coveres the surface of the sample (Fig. 4a, b), during the cycles. It represents a cumulus of salts transported by water at the surface.

Chemical analyzes showed that the whitish layer is a calcium carbonate salts, knowing that the salt dominant in these samples is calcium carbonate $\left(\mathrm{CaCO}_{3}\right)$ (about $20 \%$ ). The thickness of this layer depends on the percentage of calcium carbonate existing in the soil.

\section{Wetting of clay by infiltration}

In the first cycle of drying, the cracks are observed in the clay samples D2 and B2 showing in the Fig. 5, and shrink of the samples volume. The reorder of small aggregates has generated gradual erosion of samples and the increase of permeability from the second cycle, this reorder continuous to occur in the next cycles. For this reason, the crumbling of the aggregates is observed over wetting stages in the following swelling-shrinking cycles.

During the sixth cycle of sample D2, the temperature dropped at minus one $\left(-1{ }^{\circ} \mathrm{C}\right)$, the water has frozen. The pore volume increases and the cracks of shrinkage broaden (Fig. 5). The sample has undergone considerable deformation in both vertical and horizontal directions, due to the freezing of water. At the end of climatic cycles, the samples D2 and B2 have completely lost these textural and geotechnical characteristics.

\section{Discussion of results}

In the two path of water, the swelling occurred slowly, during the first wetting cycle, because of the low permeability of clay samples. From the second cycle, a porous network expanded in the clay structure, and improves his permeability. The drying takes place in the same manner as wetting and swelling; it occurs from the outside to the inside of sample. The volume of samples decreases with the increases of water evaporation.

Samples D1, D2, B1 and B2 have undergone significant changes in their macro-structures under the effects of climatic solicitations. The structures of the samples that have undergone capillary action have not undergone a major reorder in their macro structure, and shrinkage cracks are not, as many, compared with those observed on the samples wetted by infiltration.

The upper portion of the dried sample (D1) has undergone a bursting after the wetting of the lower part of the sample by capillary action. This behavior shows the thrust force exerted by swollen soil.

During the ascent of water, by capillary action, the salts dissolved in water are transporting to the surface of the soil. This phenomenon can be observing after drying of the soil surface. In the case of marl samples, the whitish surface appears from the first cycles. This behavior promotes the swelling phenomenon because of gradual decrease in calcium carbonates.

The calcium carbonates are a chemical stabilizer of swelling clays; their progressive decrease increases the swelling potential in clay.

The vertical deformation at the first cycle of wetting is important, but, in other cycles, it is low. Samples maintained a steady pace of shrinking and swelling starting from the fifth cycle.

\section{Evolution of microstructure clay after a cycle of shrinking and swelling}

The obtained observations from SEM images shows the evolution of the clay structure after one cycle of shrinking 


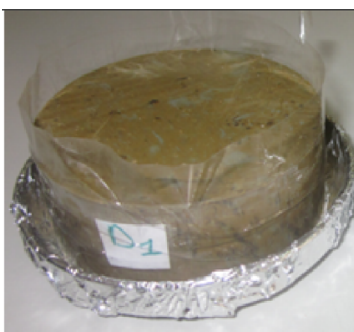

(a) Initial state

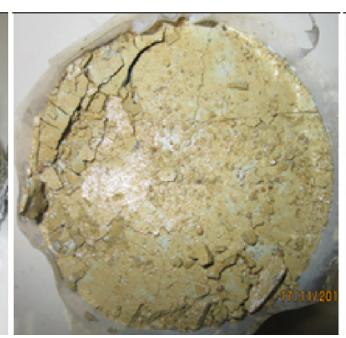

(b) cycle 1 (wet)

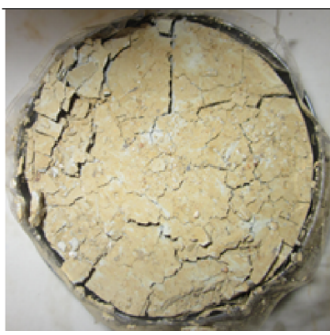

(c) cycle 1(dry)

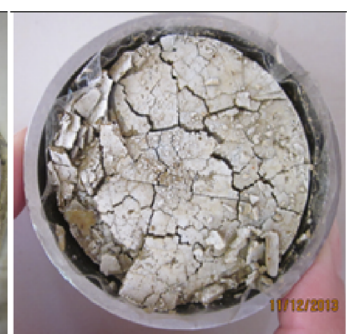

(d) cycle 3(dry)

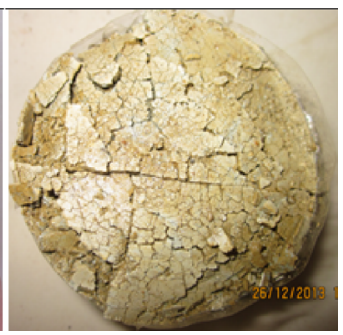

(e1) cycle 5 (dry)

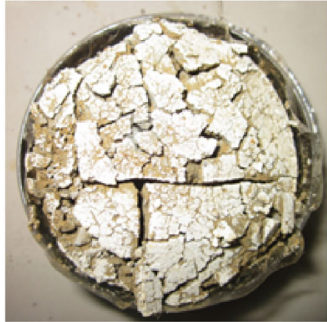

(f1) cycle 7 (dry)

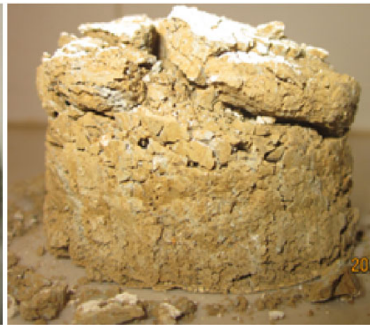

(f2) vertical show

(a) Sample D1

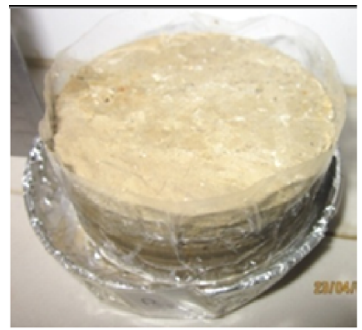

(a) Initial state

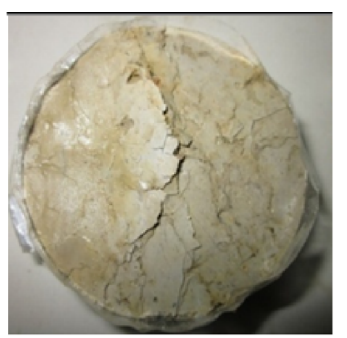

(b) cycle 1 (wet)

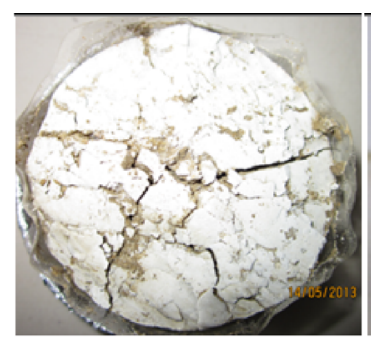

(c) cycle 3(dry)

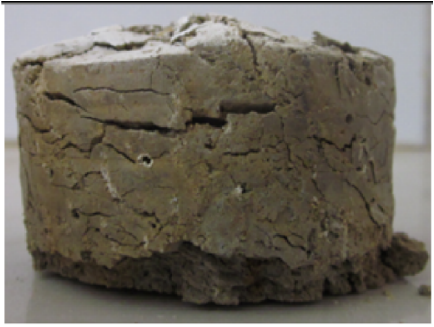

(d) cycle 4 (dry)
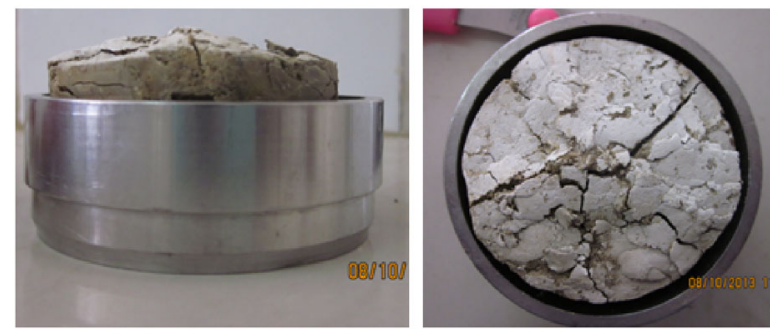

(e) Final show of simple (dry)

(b) Sample B1

Fig. 4 Evolution of the clay macrostructure during shrinking-swelling cycles, capillarity action mode

and swelling, as shown in Fig. 6a, b. This picture shows a crumbling of the clyey microparticles and the appearance of microcracks and micropores of different sizes.

The set of observations obtained after one cycle of shrinking and swelling show the opening of new cracks and increasing porosity in the samples; which causes the increase of the permeability of swelling clays. Moreover, the appearance of parallel clay sheets is preserved in the majority of SEM observations.

\section{Conclusion}

This work is realized on samples of a swelling site, which has undergone significant disorders because of the presence of swelling clay and water. This phenomenon, called shrinkage and swelling, is often characterizing by the appearance of shrinkage cracks and soil volume changes. It affects light building, but the pictures have shown that this phenomenon is more dangerous because the ground 
Fig. 5 Evolution of the clay macrostructure during shrinking-swelling cycles, infiltration mode

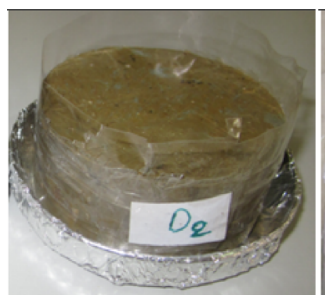

(a) Initial stat

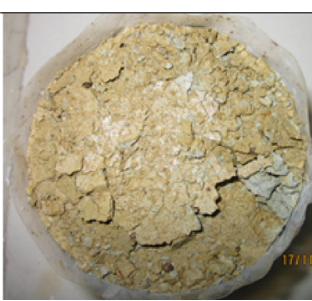

(b) cycle 1(wet)

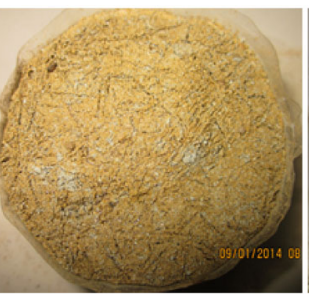

(f) cycle 6 (wet)

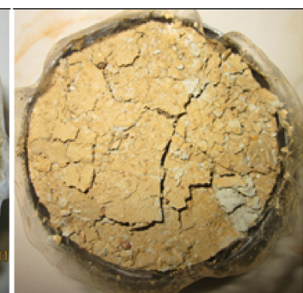

(c) cycle 1 (dry)

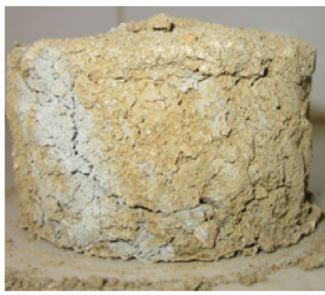

(g2) vertical show

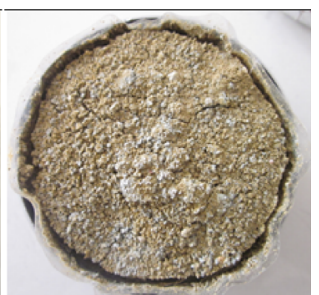

(d) cycle 5 (dry) (a) Sample D2

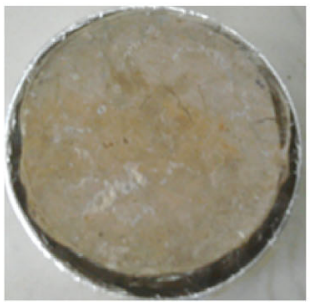

(a) Initial stat

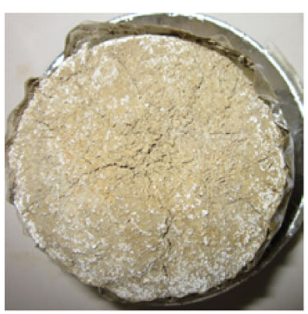

(b) cycle 2 (Dry)

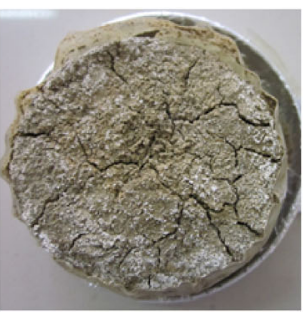

(c) cycle 4 (dry)

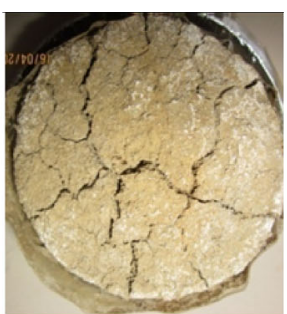

(d) cycle 7 (dry) (b) Sample B2
Table 4 Sample Identification characteristics

\begin{tabular}{llllll}
\hline Parameters & $W(\%)$ & $\gamma_{\mathrm{d}}\left(\mathrm{N} / \mathrm{m}^{3}\right)$ & $W_{\mathrm{L}}(\%)$ & $I_{\mathrm{p}}(\%)$ & $F<2 \mu \mathrm{m}(\%)$ \\
\hline Ech/D (Medea) S10 5.65 m & 11.4 & 18 & 66.3 & 39.6 & 52 \\
\hline
\end{tabular}

undergone many changes in his strength parameters, making the soil easier to move significantly on slopes. In the presence of water flow, it may be a landslide, as in the study site, or mudslides. These two phenomena are very dangerous on engineering structures.

This study complements those conducted in previous years. It shows the sensitivity of expansive soil characteristics in unsaturated conditions. It has been done on several samples of the same clay and the same behavior was observed in all samples. Both saturation modes have weakened the expansive soil by the loss of its physical and mechanical characteristics. These soils are often affected by erosion and collapse.

The analysis of infiltration saturation mode showed that the samples studied reacted to each hydric stress (shrinkage and swelling). During the first wetting cycle, the saturation of the samples took place slowly, the swelling occurred too slowly because of the low permeability of clay samples. From the second cycle, a porous network increase in the clay structure, it has the effect of improving the permeability. Drying takes place in the same manner as saturation and swelling; there occurs from the outside to the inside of a sample that shrinks more with evaporation of water.

In the mode of saturation by capillary, samples studied have undergone significant volumetric strains during saturation. The maximum vertical deformation occurs in the first cycle, and then gradually accumulates in subsequent cycles. The horizontal shrinkage increases further from one cycle to another. The pace of shrinkage and swelling tends to stabilize from the fifth cycle. The temperature effect appears in the increase in the opening of shrinkage cracks, during sample gel.

The capillary rising salt may also harm the foundations if this phenomenon is not considered. For this, it is necessary to use adequate solutions to this kind of ground 

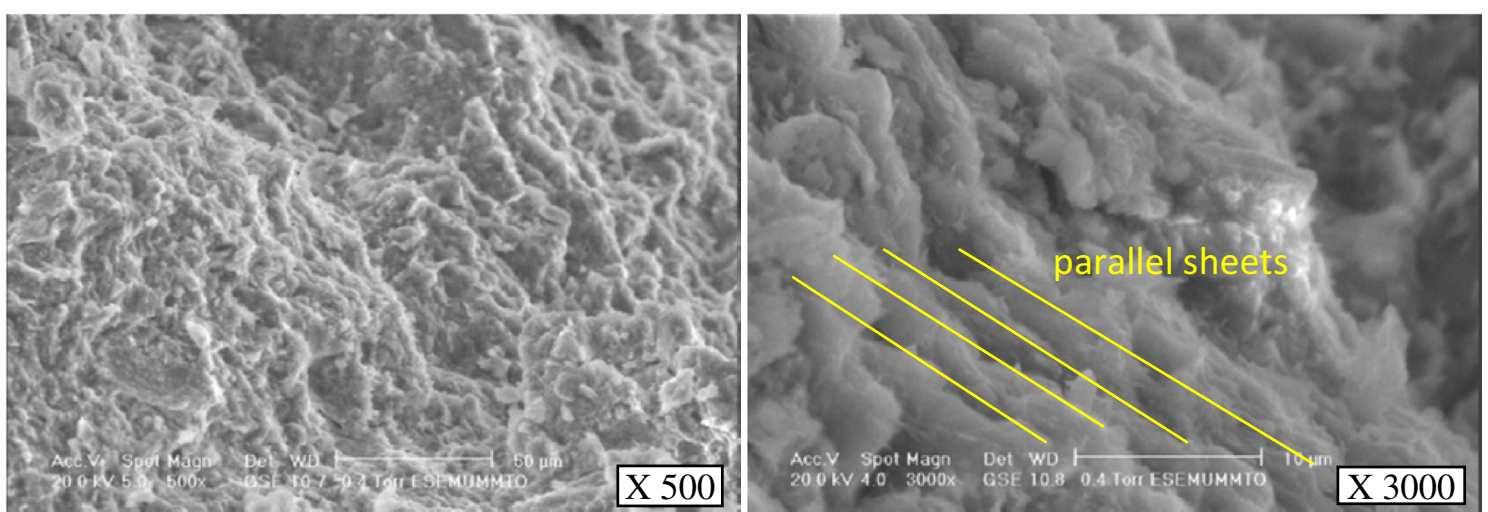

(a) Undesturbed soil
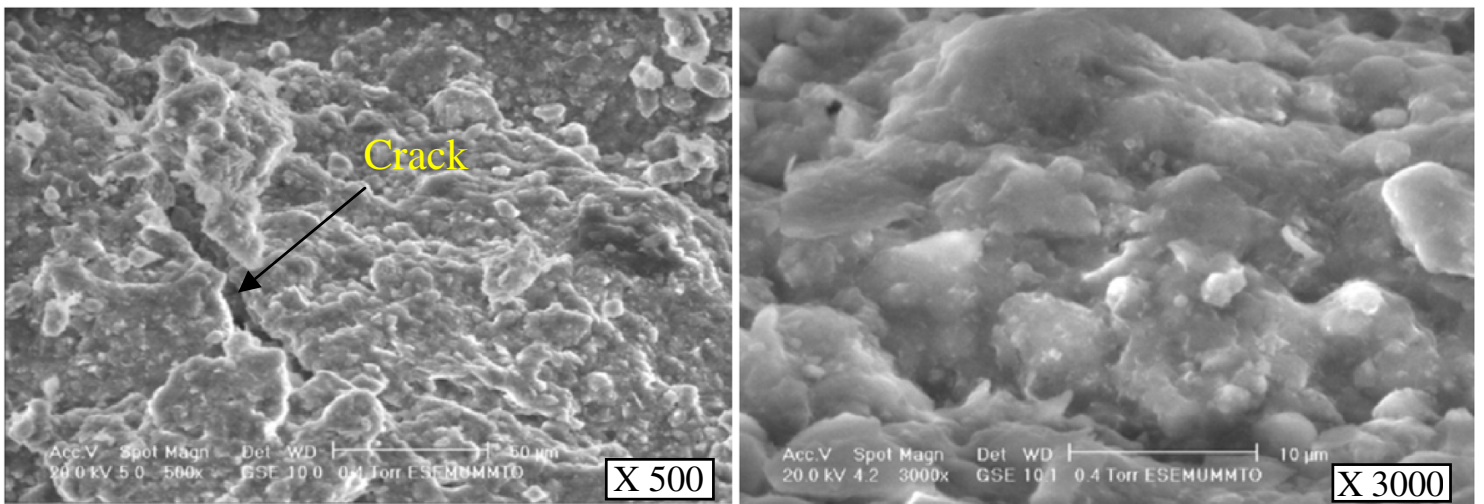

(b) The Soil has underwent one cycle of swelling shrinking

Fig. 6 SEM picture made on a sample extracted from Medea site

before it construction, such as chemical stability and the limitation of water infiltration into the soil.

\section{References}

1. Al-Hamoud AS, Basma AA, Husein Malkawi AI, Al Bashabsheh MA (1995) Cyclic swelling behavior of clays. J Geotech Eng ASCE 121(7):562-565

2. Bahar R, Kenai S (2002) Désordres dus à l'infiltration des eaux Cas de la ville d'El-Affroun. Revue française de géotechnique 101:91-103

3. Basma AA, Al-Homoud AS, Malkawi AIH, Al-Bashabsheh MA (1996) Swelling-shrinkage behavior of natural expansive clays. Appl Clay Sci 11:211-227

4. Chen FH, Ma GS (1987) Swelling and shrinkage behaviour of expansive clays. In: 6th inter. Conf. Expansive soils, New Delhi, pp $127-129$

5. Day RW (1995) Ultimate Density of a compacted clay subjected to cycles of wetting and drying. Environ Eng Geosci I(2):229-232
6. Derriche Z, Iguechtal L, Tas M (1999) Comportement des ouvrages dans les argiles expansives d'In-Amenas. Revue Française de Géotechnique 89:55-65

7. Djedid A, Bekkouche A (2001) Identification and prediction of the swelling behaviour of some soils from the Tlemcen region of Algeria. Bulletin des laboratoires des ponts et chaussées 233:69-77

8. Geremew Z, Audiguier M, Cojean R (2009) Analyse du comportement d'un sol argileux sous sollicitations hydriques cycliques. Bull Eng Geol Environ 68:421-436

9. Mouroux P, Margron P, Pinte JC (1988) La construction économique sur sols gonflants. Edit BRGM: Manuels et Méthodes, vol 14

10. Subba Rao KS, Satyadas GG (1987) Swelling potential with cycles of swelling and partial shrinkage. In: 6th Inter. Conf. Expansive soils, New Delhi, pp 137-142

11. Tripathy S, Subba Rao KS, Fredlund D (2002) Water contentvoid ratio swell-shrink paths of compacted expansive soils. Can Geotech J 39:938-959

12. Yong RN, Warkentin BP (1975) Soil properties and behavior. Elsevier, New York 